\title{
Determinants of Low Health Literacy Among Asian-American and Pacific Islanders in California
}

\author{
Monideepa B. Becerra • Benjamin J. Becerra • \\ Gem P. Daus • Leslie R. Martin
}

Received: 9 July 2014 / Revised: 27 January 2015 / Accepted: 16 February 2015 /Published online: 12 March 2015

(C) W. Montague Cobb-NMA Health Institute 2015

\begin{abstract}
Background Health literacy is a marker for how patients obtain, comprehend, communicate, and apply complex health information. Few studies exist on determinants of low health literacy among Asian-American and Pacific Islanders. The purpose of this exploratory study was to identify key determinants of low health literacy in this population using the 2007 California Health Interview Survey, a population-based survey.

Methods Low health literacy was defined as reporting either prescription bottle or written information from the doctor as being "somewhat difficult" or "very difficult" to understand, or reporting having a hard time understanding their doctor. Survey weighted univariate and multivariable regression analyses were conducted.

Results A total of 4045 participants were included in the study, representing 3,156,711 Asian-American and Pacific Islander adults in California. Factors associated with low health
\end{abstract}

\section{B. Becerra $(\bowtie)$}

Department of Health Science and Human Ecology, California State University, San Bernardino, 5500 University Parkway, San

Bernardino, CA 92407, USA

e-mail: mbecerra@csusb.edu

B. J. Becerra $\cdot$ L. R. Martin

School of Public Health, Loma Linda University, 24951 North Circle Drive, Loma Linda, CA 92350, USA

B. J. Becerra

e-mail: bbecerra@1lu.edu

L. R. Martin

e-mail: 1rmartin@1lu.edu

G. P. Daus

Asian American Studies Program, University of Maryland, College

Park, 1145 Cole Student Activities Building, College

Park, MD 20742, USA

e-mail: gdaus@umd.edu literacy were being male, low socioeconomic status, limited English language proficiency, and being foreign born.

Conclusion Results of this study highlight the current burden of low health literacy among Asian-American and Pacific Islander population and the associated factors. Targeted public health efforts to improve health literacy are needed among Asian-American and Pacific Islanders.

Keywords Health literacy · Asian-American · Pacific Islander $\cdot$ English language proficiency $\cdot$ Country of birth

\section{Background}

In recent years, a plethora of studies have highlighted the role of health literacy in various health outcomes. According to the National Assessment of Adult Literacy (NAAL), one of the most comprehensive health literacy analyses, 63 million Americans have only basic health literacy and another 30 million fall below basic health literacy levels [1]. Health literacy is defined as the "degree to which individuals have the capacity to obtain, process, and understand basic health information and services needed to make appropriate health decisions" [2]. The Patient Protection and Affordable Care Act (PPACA) of 2010 further highlights the importance of health literacy and communicating health information as an integral component of good health literacy [3-5].

Adequate health literacy, as noted in its definition, is not only comprised of reading capabilities but further requires the ability to comprehend medical information, including instructions and prescriptions, and make informed decisions when navigating the complex healthcare system [6]. Low health literacy can also be a marker for poor patient-physician communication, as patients with poor health literacy are more 
likely to report difficulties in understanding medical information and instructions provided by physicians [7, 8]. As such, low health literacy can be a significant barrier to positive health, through its associations with poor health behaviors and lower healthcare service utilization. For example, Miller and colleagues [9] reported that participants with limited literacy were $44 \%$ less likely to have knowledge about colorectal cancer screening.

Similarly, a study in Hawaii noted that low health literacy was significantly associated with various health outcomes, including diabetes, depression, and lower self-reported poor health [10]. Utilizing the 2003 NAAL data, Bennett et al. [11] evaluated the role of health literacy in both self-rated health status and preventive health behaviors among older adults. The researchers noted that health literacy was a significant mediator of self-rated health status disparities observed among various racial/ethnic and educational categories. Finally, syntheses of the empirical evidence also support the importance of health literacy to appropriate health behaviors, with Thai and George [12] reporting that low health literacy is significantly associated with poor asthma management, including higher rates of emergency department visits and hospitalization, and Zhang and colleagues [13] reporting a small but significant association between health literacy and medication adherence across a variety of domains. Cumulatively, the current literature demonstrates that limited health literacy is a significant factor associated with poorer health outcomes.

Less research, however, identifies the key sectors of specific populations at risk of low health literacy. For example, the NAAL noted that among those scoring below basic health literacy, $50 \%$ did not have a high school degree [1], although the degree to which low educational attainment can predict health literacy has not been thoroughly evaluated in the literature. Similarly, Sudore et al. [14] noted that for older adults, being male, black, having low socioeconomic status (SES), and possessing negative health status indicators (diabetes, depression, and fair/poor self-rated health) were significantly associated with low health literacy. Results such as these indicate the potential importance of race/ethnicity, gender, and SES to health literacy, but additional data are needed to better capture such factors as they exist for different populations. Moreover, experts acknowledge that while health literacy is often considered an individual factor, external contextual factors, including those related to the healthcare system, can impact the level of health literacy [15].

Understanding the key factors associated with poor health literacy, in particular cultural groups, is vital to ensure that public health efforts can effectively target those groups, yet such studies among Asian-American and Pacific Islanders (AAPI) are lacking, despite being one of the fastest growing populations in the nation $[16,17]$. Thus, understanding the correlates of low health literacy in this group is imperative. In a previous study addressing correlates of health literacy among those with chronic heart failure, the authors noted significant associations between low health literacy and being elderly, lower education, males, African-American, among others [18]. Such results demonstrate the potential role of sociodemographic characteristics related to health literacy, though similar studies among AAPIs are lacking. As such, the purpose of this study was to identify the key factors associated with low health literacy for AAPIs utilizing a population-based survey. The unique strength of such surveys is the use of replicate weights that allows results to be generalizable to the population [19]; this, in turn, provides the foundation for evidence-based decision-making.

\section{Methods}

\section{Data Source}

The present study utilized the public access 2007 adult portion of the California Health Interview Survey (CHIS). Data from additional years were excluded due to changes in the questionnaire. CHIS, considered to be the largest state health survey, is a biennial population-based survey utilizing a randomdigit-dial sample and conducted in several languages including English, Spanish, Cantonese, Mandarin, Korean, and Vietnamese [20]. A total of 51,048 noninstitutionalized adults with a California address and telephone number were included in the 2007 survey. CHIS researchers employed two distinct methods of addressing missing data: random selection from observed distribution of respondents and hot deck imputation without replacement. CHIS utilizes iterative raking in its complex survey design in turn allowing for improved variance estimates and results applicable to California residents. Additional details of CHIS and its methodology can be found elsewhere in the literature [21]. Adult AAPI respondents were included in the present study resulting in a total of 4045 participants $(n)$, representing a population estimate $(N)$ of 3,156 , 711 adults.

\section{Measures}

CHIS 2007 asked the following questions, which have been previously used in the literature as proxy measures of health literacy [22]: "When you get written information at a doctor's office, would you say that it is very easy, somewhat easy, somewhat difficult, or very difficult to understand?" and "When you read the instructions on a prescription bottle, would you say that it is very easy, somewhat easy, somewhat difficult, or very difficult to understand?" In this study, low health literacy was defined as answering "somewhat difficult" or "very difficult" to either of these questions. Additionally, we included participants who said "yes" to the question "The last time you saw a doctor, did you have a hard time 
understanding the doctor?" to account for verbal, as well as written, aspects of health literacy. As a result, a total of 1063 participants (representing 751,812 California residents) with low health literacy were identified.

CHIS 2007 further asked respondents who reported speaking language(s) at home other than English the following questions related to English proficiency: "Since you speak a language other than English at home, we are interested in your own opinion of how well you speak English. Would you say you speak English (well, very well, not well, not at all)." Limited English language proficiency (LEP) was included as a potential predictor of low health literacy and in this study was defined as those reporting "not well" or "not at all," consistent with previous research [22]. Other predictor variables included CHIS-provided variable of age and additional recoded variables including the following: gender (female versus male), education (not a college graduate versus college graduate based on natural breakpoint in the population), poverty (below $200 \%$ federal poverty level [FPL] versus at or above $200 \%$ FPL), insurance status (not insured all past 12 months versus insured all past 12 months), geographic location (rural versus urban), and country of birth (foreign born versus US born). In addition, AAPI ethnicity was categorized as Chinese, Filipino, South Asian, Japanese, Korean, Vietnamese, and other (including Cambodian, Pacific Islander, other single Asian race, multiple Asian race).

\section{Statistical Analysis}

Descriptive analyses were conducted to assess the distributions of sociodemographic and other characteristics within the study sample followed by both univariate and multivariable analyses. Differences in least square means using survey-weighted linear regression using the $t$ statistic, for continuous variable of age, and Rao-Scott Chi-square analyses using design-based $F$ values, were utilized for all univariate analyses. Survey-weighted multivariable logistic regression was further utilized to assess the key determinants of low health literacy. All predictor variables were included in the multivariable analyses. All assumptions of regression analyses were assessed, and due to the survey's multistage sampling design, a jackknife approach was used to compute standard errors [23]. SAS 9.4 (SAS Institute, Inc., Cary, NC) was utilized for all analyses, and statistical significance for all testing was set at $p<.05$.

\section{Results}

\section{Respondent Characteristics}

Table 1 provides the various sociodemographic characteristics of the study sample. The highest percent of the AAPI
Table 1 Sociodemographic and other characteristics of study sample

\begin{tabular}{|c|c|c|}
\hline $\begin{array}{l}\text { Mean age }(95 \% \mathrm{CI}) \\
43.51(42.96,44.06)\end{array}$ & $\begin{array}{l}\text { Sample size } \\
(n)\end{array}$ & $\begin{array}{l}\text { Weighted \% } \\
(95 \% \mathrm{CI})\end{array}$ \\
\hline \multicolumn{3}{|l|}{ Gender } \\
\hline Female & 2384 & $54.16(53.20,55.13)$ \\
\hline Male & 1661 & $45.84(44.87,46.80)$ \\
\hline \multicolumn{3}{|l|}{ Ethnicity } \\
\hline Chinese & 1209 & $27.90(26.84,28.96)$ \\
\hline Filipino & 668 & $25.52(24.64,26.40)$ \\
\hline South Asian & 423 & $10.87(9.60,12.13)$ \\
\hline Japanese & 436 & $7.30(6.26,8.33)$ \\
\hline Korean & 580 & $8.49(7.82,9.16)$ \\
\hline Vietnamese & 453 & $11.10(10.06,12.14)$ \\
\hline Other & 275 & $8.84(7.67,10.01)$ \\
\hline \multicolumn{3}{|l|}{ Poverty } \\
\hline$<200 \% \mathrm{FPL}$ & 1132 & $27.61(25.74,29.48)$ \\
\hline$\geq 200 \% \mathrm{FPL}$ & 2913 & $72.39(70.52,74.26)$ \\
\hline \multicolumn{3}{|l|}{ Education } \\
\hline Not college graduate & 1479 & $42.60(40.28,44.91)$ \\
\hline College graduate & 2566 & $57.40(55.09,59.72)$ \\
\hline \multicolumn{3}{|l|}{ Insurance status } \\
\hline Not insured all past 12 months & 544 & $14.92(13.13,16.71)$ \\
\hline Insured all past 12 months & 3501 & $85.08(83.29,86.87)$ \\
\hline \multicolumn{3}{|l|}{ Geographic location } \\
\hline Rural & 172 & $3.75(2.99,4.51)$ \\
\hline Urban & 3873 & $96.25(95.50,97.01)$ \\
\hline \multicolumn{3}{|l|}{ English language proficiency } \\
\hline Limited & 939 & $19.03(17.20,20.86)$ \\
\hline English proficient & 3106 & $80.97(79.14,82.80)$ \\
\hline \multicolumn{3}{|l|}{ Country of birth } \\
\hline Foreign born & 3070 & $73.34(70.80,75.87)$ \\
\hline US born & 975 & $26.66(24.13,29.20)$ \\
\hline \multicolumn{3}{|l|}{ Health literacy } \\
\hline Low & 1063 & $23.82(21.79,25.85)$ \\
\hline High & 2982 & $76.18(74.15,78.21)$ \\
\hline
\end{tabular}

From CHIS 2007

CI confidence interval, FPL federal poverty level

population in the study were Chinese (28\%), followed by Filipino (26\%). A majority ( $>50 \%$ ) of study population were females, were living at or above the $200 \%$ FPL, were college graduates, had been insured for all of the past 12 months, lived in urban areas, reported being English proficient, and were foreign born. The mean age of the sample in the study was approximately 44 years. Twenty-four percent of the study population reported low health literacy.

Univariate Analysis

Results from the univariate analysis, shown in Table 2, demonstrate significant differences in health literacy across all 
Table 2 Univariate analysis of sociodemographic and other characteristics of study population by health literacy level

\begin{tabular}{|c|c|c|c|c|c|}
\hline \multirow{3}{*}{$\begin{array}{l}\text { sociodemographic and other } \\
\text { characteristics of study } \\
\text { population by health literacy level }\end{array}$} & \multirow[t]{3}{*}{ Mean age $(95 \% \mathrm{CI}) *$} & \multicolumn{2}{|c|}{ Low health literacy } & \multicolumn{2}{|c|}{ Adequate health literacy } \\
\hline & & \multicolumn{2}{|c|}{$48.07(46.62,49.53)$} & \multicolumn{2}{|c|}{$42.08(41.33,42.83)$} \\
\hline & & Sample $(n)$ & Weighted \% (CI) & Sample $(n)$ & Weighted \% (CI) \\
\hline & \multicolumn{5}{|l|}{ Gender } \\
\hline & Female & 625 & $50.40(46.33,54.47)$ & 1759 & $55.34(53.78,56.90)$ \\
\hline & Male & 438 & $49.60(45.53,53.67)$ & 1223 & $44.66(43.10,46.22)$ \\
\hline & \multicolumn{5}{|l|}{ Ethnicity* } \\
\hline & Chinese & 401 & $40.82(36.08,45.56)$ & 808 & $23.86(22.30,25.41)$ \\
\hline & Filipino & 63 & $11.13(7.37,14.90)$ & 606 & $30.01(28.52,31.50)$ \\
\hline & South Asian & 58 & $5.57(3.57,7.57)$ & 365 & $12.53(10.88,14.17)$ \\
\hline & Japanese & 69 & $5.62(3.45,7.79)$ & 367 & $7.82(6.68,8.96)$ \\
\hline & Korean & 217 & $10.59(8.62,12.55)$ & 363 & $7.83(6.92,8.74)$ \\
\hline & Vietnamese & 185 & $17.34(14.34,20.35)$ & 268 & $9.14(7.96,10.32)$ \\
\hline & Other & 70 & $8.93(6.45,11.41)$ & 205 & $8.81(7.35,10.28)$ \\
\hline & \multicolumn{5}{|l|}{ Poverty* } \\
\hline & $<200 \% \mathrm{FPL}$ & 488 & $45.37(40.78,49.97)$ & 644 & $22.06(19.92,24.20)$ \\
\hline & $\geq 200 \% \mathrm{FPL}$ & 575 & $54.63(50.03,59.22)$ & 2338 & $77.94(75.80,80.08)$ \\
\hline & \multicolumn{5}{|l|}{ Education* } \\
\hline & Not college graduate & 584 & $57.56(52.95,62.18)$ & 895 & $37.92(35.20,40.64)$ \\
\hline & College graduate & 479 & $42.44(37.82,47.05)$ & 2087 & $62.08(59.36,64.80)$ \\
\hline & \multicolumn{5}{|l|}{ Insurance status* } \\
\hline & Not insured all past 12 months & 211 & $20.48(16.82,24.13)$ & 333 & $13.18(11.14,15.23)$ \\
\hline & Insured all past 12 months & 852 & $79.52(75.87,83.18)$ & 2649 & $86.82(84.77,88.86)$ \\
\hline & \multicolumn{5}{|l|}{ Geographic location* } \\
\hline & Rural & 24 & $2.26(1.02,3.50)$ & 148 & $4.22(3.29,5.14)$ \\
\hline & Urban & 1039 & $97.74(96.50,98.98)$ & 2834 & $95.78(94.86,96.71)$ \\
\hline & \multicolumn{5}{|l|}{ English language proficiency* } \\
\hline & Limited & 541 & $46.08(41.21,50.94)$ & 398 & $10.57(9.09,12.05)$ \\
\hline From CHIS 2007 & English proficient & 522 & $53.92(49.06,58.79)$ & 2584 & $89.43(87.95,90.91)$ \\
\hline$C I$ confidence interval for mean & \multicolumn{5}{|l|}{ Country of birth* } \\
\hline or weighted percent, $F P L$ federal & Foreign born & 948 & $87.34(84.42,90.26)$ & 2122 & $68.96(65.76,72.16)$ \\
\hline$*_{p}<.05$ & US born & 115 & $12.66(9.74,15.58)$ & 860 & $31.04(27.84,34.24)$ \\
\hline
\end{tabular}

\section{From CHIS 2007}

$C I$ confidence interval for mean or weighted percent, FPL federal poverty level

${ }^{*} p<.05$ examined sociodemographic and other characteristics, with the exception of gender, in this AAPI population. For example, respondents with low health literacy had a significantly higher mean age (48 years) compared to those with adequate health literacy (42 years). Among those with low health literacy, highest proportion was Chinese (41\%), followed by Vietnamese (17\%). A higher percent of respondents with low health literacy lived in poverty, were not a college graduate, were not insured all past 12 months, lived in urban area, had limited English language proficiency, and were foreign born, as compared to those with adequate health literacy. All such variables as noted in Table 2 were included for full regression model.

\section{Multivariable Analysis}

Table 3 demonstrates the results from logistic regression analysis. Due to the nonlinear distribution of age, the variable was trichotomized to $18-44,45-64$, and $\leq 65$ years for the regression model. Low health literacy was significantly associated with living below the poverty level (adjusted odds ratio $(\mathrm{AOR})=1.45)$, not being a college graduate $(\mathrm{AOR}=1.40)$, having limited English language proficiency $(\mathrm{AOR}=3.46)$, and being foreign born $(\mathrm{AOR}=2.21)$. On the other hand, females were less likely to have low health literacy (AOR= $0.77)$ as compared to males. Filipino $(\mathrm{AOR}=0.32)$, South Asian $(\mathrm{AOR}=0.40)$, and Korean $(\mathrm{AOR}=0.60)$ subgroups were less likely to have low health literacy as compared to 
Table 3 Multivariable logistic regression adjusted odds ratios (and $95 \% \mathrm{CI}$ ) of low health literacy of study population

\begin{tabular}{|c|c|c|}
\hline & OR & $95 \% \mathrm{CI}$ \\
\hline \multicolumn{3}{|l|}{ Age (ref. $=18-44$ years) } \\
\hline 45-64 years & 1.02 & $(0.78,1.33)$ \\
\hline$<65$ years & 1.16 & $(0.84,1.60)$ \\
\hline \multicolumn{3}{|l|}{ Ethnicity (ref.=Chinese) } \\
\hline Filipino & 0.32 & $(0.19,0.52)^{* * *}$ \\
\hline South Asian & 0.40 & $(0.25,0.65)^{* *}$ \\
\hline Japanese & 0.88 & $(0.53,1.46)$ \\
\hline Korean & 0.60 & $(0.41,0.87)^{*}$ \\
\hline Vietnamese & 0.71 & $(0.51,1.00)$ \\
\hline Other & 0.82 & $(0.51,1.31)$ \\
\hline \multicolumn{3}{|l|}{ Gender (ref.=male) } \\
\hline Female & 0.77 & $(0.60,0.97)^{*}$ \\
\hline \multicolumn{3}{|l|}{ Poverty (ref. $=\geq 200 \%$ FPL) } \\
\hline$<200 \% \mathrm{FPL}$ & 1.45 & $(1.05,2.00)^{*}$ \\
\hline \multicolumn{3}{|l|}{ Education (ref.=college graduate) } \\
\hline Not college graduate & 1.40 & $(1.07,1.84)^{*}$ \\
\hline \multicolumn{3}{|l|}{$\begin{array}{l}\text { Insurance status } \\
\text { (ref.=insured all } 12 \text { months) }\end{array}$} \\
\hline Not insured all past 12 months & 1.35 & $(0.97,1.89)$ \\
\hline \multicolumn{3}{|l|}{ Geographic location (ref.=urban) } \\
\hline Rural & 0.77 & $(0.41,1.44)$ \\
\hline \multicolumn{3}{|l|}{$\begin{array}{l}\text { English language proficiency } \\
\text { (ref.=English proficient) }\end{array}$} \\
\hline Limited & 3.46 & $(2.43,4.93)^{* * *}$ \\
\hline \multicolumn{3}{|l|}{ Country of birth (ref.=US born) } \\
\hline $\begin{array}{c}\text { Foreign born } \\
\text { c-statistic }=0.766\end{array}$ & 2.21 & $(1.50,3.25)^{* * *}$ \\
\hline
\end{tabular}

From CHIS 2007

$O R$ odds ratio, $C I$ confidence interval, $F P L$ federal poverty level ${ }^{*} p<.05 ; * * p<.005 ; * * * p<.0001$

Chinese. Age, insurance status, geographic location (rural/ urban), ethnic groups of Japanese, Vietnamese, and other AAPI subgroups were not associated with low health literacy. In addition, the c-statistic of the model, which measures the area under the receiver operating characteristic curve, was noted to be 0.766 , indicating a reasonably strong goodness of fit.

\section{Discussion}

Few studies to date have evaluated the correlates of health literacy, and to our knowledge, none have been conducted among AAPIs. By utilizing a population-based survey, we were able to analyze the key sociodemographic correlates of low health literacy among AAPIs in California. The results of this study highlighted several such significant factors associated with low health literacy among the said population. Our results noted higher odds of low health literacy among those living in poverty, not being a college graduate, having limiting English language proficiency, and being foreign born. Such results are consistent with previous literature on the importance of such sociodemographic variables.

The results of this study demonstrated the importance of education in health literacy, which has further been noted in the literature. For example, a study among Chinese adults [24] noted that increasing level of education was significantly associated with higher health literacy scores in their population. In a study among populations in Tennessee and Pennsylvania, researchers noted that various sociodemographic characteristics, including low education, were significantly associated with low health literacy [14]. Studies further suggest that a complex interplay exists between educational status and health, with increasing education linked to the learning of health-specific information, skill building, and other factors with direct and indirect effects on socioeconomic status [25]. This bodes well for the AAPI subgroups with high prevalence of college degree, such as Indians [26]. However, these trends may not reflect all AAPI subgroups, and improvements in health literacy could be attained through scopes of educational attainment, such as accessibility to health information.

In addition, other researchers indicate that certain sectors of AAPI population, such as second generation, may place less emphasis on education than their immigrant counterparts. For example, a study among Chinese immigration and Chinese second-generation students noted that while the former valued rigorous school work, the latter showed lower interest in school work and academic success [27]. Given the significant association noted with education and health literacy and aforementioned evidence in low educational attainment among the population, public health efforts to improve health literacy among such populations are necessary.

In today's utilization of electronic health records with the implementation of the Health Information Technology for Economic and Clinical Act [28], English language proficiency remains a key. For example, a study [29] among federally qualified health centers in New York City noted that odds of receiving an access code for electronic records and repeatedly using such portals were higher among those who spoke English. As such, those with LEP remain significantly disadvantaged at utilizing such records and making informed health decisions.

Given that the results of this study further demonstrated the association between LEP and low health literacy, efforts targeted at making linguistically and culturally tailored health information readily available to AAPI should be integrated as national priority. The Plain Language initiative of the National Institutes of Health [30], based on the President Obama's Plain Writing Act of 2010 [31], could provide a foundation of best 
practice for the nation's health care organizations to implement in order to improve health literacy of populations. Moreover, it has been noted that AAPIs tend to prefer face-to-face communication with health care professionals rather than obtaining health information from written or online sources $[32,33]$, suggesting that LEP may be an even greater barrier for such population individuals.

In addition, our study noted that foreign-born AAPIs are more likely to have low health literacy. Such results are consistent with previous studies among Hispanic population that noted less acculturation to be significantly associated with low health literacy [34]. Such results highlight the need for targeted interventions for new immigrants to ensure adequate understanding of the complex healthcare system in the nation and in turn appropriate health outcomes.

On the other hand, our study noted several factors to be associated with lower odds of having low health literacy. We noted that females are less likely to report low health literacy. Such results are partially consistent with previous literature, as while some researchers have noted a similar trend [18], others reported no significant association with gender [34]. Further studies are warranted to address the complex interplay between gender and health literacy as gender-specific cultural factors [35], and communication strategies [36] may impact health decision-making and/or patient-physician communication. In addition, the differences noted based on AAPI subgroup highlights the need for further research by AAPI subgroup and the unique cultural characteristics that may determine health literacy in such populations.

The results of this study should be interpreted in the context of some limitations. The use of secondary data analysis limits our ability to potentially assess other variables that may be associated with health literacy but were not collected in CHIS. Given that most of our study population resided in urban areas, the potential underestimation of rural residents may posit a limitation, and thus, further studies among such populations are needed. Due to limited sample size, we could not provide Asian ethnicity-specific analyses, including Pacific Islanders as a separate group. Finally, the cross-sectional nature of CHIS limits the drawing of causal conclusions; only associations and group differences can be established [37].

Despite such limitations, this study provided one of the first assessments of determinants of health literacy among AAPIs, utilizing a population-based survey and provides the foundation for future research and practice. A study [38] noted that most health information resulting from search engines required high reading levels. Thus, in order to improve population health outcomes, health care organizations today would benefit from making critical health information available in a variety of languages central to their service areas. Similarly, cultural beliefs could significantly play a factor in health and associated behaviors [39]. As such, culturally competent health literacy materials made readily available to such populations could vastly improve healthcare service utilization, adherence, and management.

Additionally, if an individual is unable to understand health information, then, the burden not only for translating but also for explaining may be passed to a third party, such as a younger family member [14]. As such, future studies should further assess the importance of third party's educational and health literacy status in patient health outcomes. Moreover, while the present study was unable to assess AAPI subgroup-specific analysis, future studies could enhance the current body of literature by conducting subgroup analysis to highlight the uniqueness of the diverse AAPI population and associated health literacy status. The current empirical evidence notes similar differences in health literacy [10] across AAPI subgroups and for other health-related outcomes, such as to binge drinking, physical activity, and diet [40, 41]. Finally, given that low English language proficiency and country of birth were noted as significant predictors of low health literacy in this study, future studies could expand upon other immigration-related variables and even incorporation of acculturation as potential factors associated with health literacy among the AAPI population.

Ethical Statement The study was reviewed and considered exempt by the Institutional Board of California State University, San Bernardino, and Loma Linda University. No animal or human studies were carried out by the authors for this article.

Conflict of Interest Monideepa B. Becerra declares no conflict of interest. Benjamin J. Becerra declares no conflict of interest.

Gem Daus declares no conflict of interest.

Leslie Martin declares no conflict of interest.

There are no funding sources for this project.

\section{References}

1. Institute of Education Sciences. National Assessment of Adult Literacy (NAAL)-Key Findings [Internet]. 2013 [cited 2013 Jul 29]. Available from: http://nces.ed.gov/naal/kf_demographics.asp

2. Lynn N-B, Panzer AM, Kindig DA, Editors, Committee on Health Literacy. Health literacy: a prescription to end confusion. Washington: The National Academies Press; 2004. p. 368.

3. ASPA. Read the Law [Internet]. 2013 [cited 2014 Mar 2]. Available from: http:/www.hhs.gov/healthcare/rights/law/

4. Association of University Centers on Disabilities. Title V of the Patient Protection and Affordable Care Act, Health Care Workforce Provisions [Internet]. 2010. Available from: https://www.aucd.org/ docs/policy/health_care/Section $\% 20$ by $\% 20$ Section $\% 20$ Summary $\%$ 20 of $\% 20$ Health $\% 20$ Care $\% 20$ Workforce.pdf

5. CDC. Health Literacy | Learn About Health Literacy [Internet]. 2011 [cited 2014 Mar 2]. Available from: http://www.cdc.gov/ healthliteracy/learn/index.html

6. National Network of Libraries on Medicine. Health Literacy [Internet]. 2011 [cited 2012 Feb 15]. Available from: http://nnlm. gov/outreach/consumer/hlthlit.html 
7. Schillinger D, Piette J, Grumbach K, Wang F, Wilson C, Daher C, et al. Closing the loop: physician communication with diabetic patients who have low health literacy. Arch Intern Med. 2003;163(1): 83-90.

8. Schillinger D, Bindman A, Wang F, Stewart A, Piette J. Functional health literacy and the quality of physician-patient communication among diabetes patients. Patient Educ Couns. 2004;52(3):315-23.

9. Miller DP, Brownlee CD, McCoy TP, Pignone MP. The effect of health literacy on knowledge and receipt of colorectal cancer screening: a survey study. BMC Fam Pract. 2007;8:16.

10. Sentell T, Baker KK, Onaka A, Braun K. Low health literacy and poor health status in Asian Americans and Pacific Islanders in Hawai'i. J Health Commun. 2011;16 Suppl 3:279-94.

11. Bennett IM, Chen J, Soroui JS, White S. The contribution of health literacy to disparities in self-rated health status and preventive health behaviors in older adults. Ann Fam Med. 2009;7(3):204-11.

12. Thai AL, George M. The effects of health literacy on asthma selfmanagement. J Asthma Allergy Educ. 2010;1(2):50-5.

13. Zhang NJ, Terry A, McHorney CA. Impact of health literacy on medication adherence: a systematic review and meta-analysis. Ann Pharmacother. 2014 Mar 11

14. Sudore RL, Mehta KM, Simonsick EM, Harris TB, Newman AB, Satterfield S, et al. Limited literacy in older people and disparities in health and healthcare access. J Am Geriatr Soc. 2006;54(5):770-6.

15. Brach C, Keller D, Hernandez L, Baur C, Parker R, Dreyer B, et al. Ten attributes of health literate health care organizations [Internet]. 2012. Available from: http://iom.edu/ /media/Files/PerspectivesFiles/2012/Discussion-Papers/BPH_Ten_HLit_Attributes.pdf

16. Hoeffel EM, Rastogi S, Kim MO, Shahid H. 2010 Census Publications - U.S. Census Bureau [Internet]. 2012 [cited 2012 Nov 25]. Available from: http://www.census.gov/prod/cen2010/ briefs/c2010br-11.pdf

17. US Census Bureau Public Information Office. Facts for features [Internet]. 2011 [cited 2014 Sep 3]. Available from: https://www. census.gov/newsroom/releases/archives/facts_for_features_special_ editions/cb11-ff06.html

18. Morrow D, Clark D, Tu W, Wu J, Weiner M, Steinley D, et al. Correlates of health literacy in patients with chronic heart failure. The Gerontologist. 2006;46(5):669-76.

19. Institute of Medicine (US) Committee on a national surveillance system for cardiovascular and select chronic diseases. Existing Surveillance Data Sources and Systems [Internet]. 2011 [cited 2014 Mar 3]. Available from: http://www.ncbi.nlm.nih.gov/books/ NBK83157/

20. UCLA Center for Health Policy Research. About CHIS [Internet]. 2012 [cited 2014 Apr 13]. Available from: http://healthpolicy.ucla. edu/chis/about/Pages/what-is-chis.aspx

21. California Health Interview Survey, 2007. CHIS 2007 methodology series, sample design [Internet]. [cited 2013 Jul 28]. Available from: http://healthpolicy.ucla.edu/chis/design/Documents/CHIS2007 method1.pdf

22. Sentell T, Braun K. Low health literacy, limited English proficiency, and health status in Asians, Latinos, and other racial/ethnic groups in California. J Health Commun. 2012;17 Suppl 3:82-99.

23. California Health Interview Survey. HIS 2007 methodology series: report 5-weighting and variance estimation [Internet]. 2009. Available from: http://healthpolicy.ucla.edu/chis/design/Documents/ CHIS2007 method5.pdf

24. Sun X, Shi Y, Zeng Q, Wang Y, Du W, Wei N, et al. Determinants of health literacy and health behavior regarding infectious respiratory diseases: a pathway model. BMC Public Health. 2013;13(1):261.

25. Desjardins R. The determinants of health literacy proficiency. Unpublished work. Denmark: Danish School of Education, Aarhus University; 2010.

26. Piccorossi M. Asian Americans [Internet]. Pew research center's social \& demographic trends project. 2012 [cited 2014 Mar 17]. Available from: http://www.pewsocialtrends.org/asianamericansgraphics/

27. Kaufman J. The interplay between social and cultural determinants of school effort and success: an investigation of Chinese-immigrant and second-generation Chinese Students' perceptions toward school*. Soc Sci Q. 2004;85(5):1275-98.

28. U.S. Department of Health and Human Services. HITECH Act Enforcement Interim Final Rule [Internet]. [cited 2014 Apr 14]. Available from: http://www.hhs.gov/ocr/privacy/hipaa/ administrative/enforcementrule/hitechenforcementifr.html

29. Ancker JS, Barrón Y, Rockoff ML, Hauser D, Pichardo M, Szerencsy A, et al. Use of an electronic patient portal among disadvantaged populations. J Gen Intern Med. 2011;26(10):1117-23.

30. National Institutes of Health. Plain language [Internet]. [cited 2014 Apr 14]. Available from: http://www.nih.gov/clearcommunication/ plainlanguage/index.htm

31. Sunstein C. Final Guidance on Implementing the Plain Writing Act of 2010 [Internet]. 2011. Available from: http://www.whitehouse.gov/ sites/default/files/omb/memoranda/2011/m11-15.pdf

32. Ngo-Metzger Q, Hayes GR, Chen Y, Cygan R, Garfield CF. Improving communication between patients and providers using health information technology and other quality improvement strategies: focus on low-income children. Med Care Res Rev. 2010;67(5 suppl):246S-67S

33. Yip M-P. A health literacy model for limited English speaking populations: sources, context, process, and outcomes. Contemp Nurse. 2012;40(2):160-8.

34. Boyas JF. Correlates of health literacy among latinos in Arkansas. Soc Work Public Health. 2013;28(1):32-43.

35. Ray-Mazumder S. Role of gender, insurance status and culture in attitudes and health behavior in a US Chinese student population. Ethn Health. 2001;6(3-4):197-209.

36. Street RL. Gender differences in health care provider-patient communication: are they due to style, stereotypes, or accommodation? Patient Educ Couns. 2002;48(3):201-6.

37. Carlson MDA, Morrison RS. Study design, precision, and validity in observational studies. J Palliat Med. 2009;12(1):77-82.

38. Berland GK, Elliott MN, Morales LS, Algazy JI, Kravitz RL, Broder MS, et al. Health information on the Internet: accessibility, quality, and readability in English and Spanish. JAMA J Am Med Assoc. 2001;285(20):2612-21.

39. Shaw SJ, Huebner C, Armin J, Orzech K, Vivian J. The role of culture in health literacy and chronic disease screening and management. J Immigr Minor Health. 2008;11(6):460-7.

40. Becerra MB, Herring P, Hopp Marshak H, Banta JE. Association between acculturation and binge drinking among Asian-Americans: results from the California Health Interview Survey. J Addict [Internet]. 2013 Dec 11 [cited 2013 Dec 12];2013. Available from: http://www.hindawi.com/journals/jad/2013/248196/abs/

41. Maxwell AE, Crespi CM, Alano RE, Sudan M, Bastani R. Health risk behaviors among five Asian American subgroups in California: identifying intervention priorities. J Immigr Minor Health Cent Minor Public Health. 2012;14(5):890-4. 